\title{
Jóvenes y cuidado: un análisis sobre las prácticas de crianza y cuidado de padres varones de un barrio popular del Gran La Plata (Argentina)
}

\author{
Cintia Hasicic \\ Becaria doctoral IIGG UBA CONICET, Universidad de Buenos Aires, Argentina \\ Email: cintiahasicic@yahoo.com.ar
}

\begin{abstract}
Resumen: En el marco de nuestra investigación doctoral sobre paternidades juveniles en barrios populares, en este artículo en particular presentamos algunos hallazgos preliminares y reflexiones sobre las prácticas de cuidado que desarrollan los jóvenes varones en sus hogares, a partir de su propio testimonio.Indagamos especialmente enlas decisiones y prácticas de cuidado de sus hijos/as, como también en la distribución de tareas y sus prácticas domésticas cotidianas. Con ese propósito, realizamos cuarenta entrevistas semiestructuradas a jóvenes padres ${ }^{1}$ residentes de un barrio popular del Gran La Plata, Buenos Aires (Argentina) durante el período 2013-2015. Si bien la responsabilidad del cuidado continúa centrada en las mujeres, sostenemos que los entrevistados realizan prácticas de cuidado (que denominaremos cuidados administrativos y/o lúdicos).observando un mayor involucramiento en la crianza en comparación con sus propios padres.
\end{abstract}

Palabras clave: Cuidados, paternidades, juventudes, barrios populares

\section{Youth and care: an analysis of the parenting and care practices of male parents in a popular neighborhood of Gran La Plata}

\begin{abstract}
In the framework of our doctoral research on youth paternity in popular neighborhoods, in this article we present some findings and reflections on the care practices that young men develop in their homes, based on their own testimony. We investigate especially in the decisions and practices of taking care of their children, as well as in the distribution of tasks and their daily domestic practices. With that purpose, we conducted 40 semi-structured interviews with young resident parents of a popular neighborhood of Gran La Plata, Buenos Aires (Argentina) during the period 2013-2015. Although the responsibility for care continues to be focused on women, we maintain that the interviewees perform care practices (which we will call administrative and / or playful care). observing a greater involvement in parenting compared to their own parents.
\end{abstract}

Keywords: Care, paternities, youths, popular neighborhoods 


\section{Juventude e cuidados: uma análise das práticas de formaçãoe de cuidado de pais do sexo masculino de um bairro popular de Gran La Plata}

Resumo: No âmbito de nossa pesquisa de doutorado sobre a paternidade juvenil em bairros populares, neste artigo apresentamos alguns achados preliminares e reflexões sobre as práticas de cuidado que desenvolvem os jovens em seus lares, a partir de seu próprio depoimento. Indagamos especialmente nas decisões e práticas de cuidar de seus filhos, bem como na distribuição de tarefas e suas práticas domésticas diárias. Com esse objetivo, realizamos 40 entrevistas semiestruturadas com jovens pais residentes de um bairro popular de Gran La Plata, Buenos Aires (Argentina). durante o período de 2013-2015. Embora a responsabilidade pelo cuidado continue focada na mulher, sustentamos que os entrevistados realizam práticas de cuidado (que chamaremos de cuidados administrativo e/ ou lúdicos). observando um maior envolvimento na formação dos filhos, em comparação aos seus próprios pais.

Palavras-chave: Cuidado, paternidade, juventude, bairros populares

$* * *$

\section{Introducción}

El estudio de las paternidades juveniles es un tema emergente en el área de las Ciencias Sociales ${ }^{2}$. La inclusión de los varones en temas vinculados a la salud reproductiva y cuidados fue creciendo paulatinamente y de manera indirecta, a partir de investigaciones feministas centradas en la familia y la maternidad.

En varios países de América Latina, la concepción y la crianza de los/ as hijos/as son aún experiencias atribuidas a las mujeres que incluyen discretamente al padre. Sin embargo, recientes estudios(Levtov,2015; Sarkadi, 2008) señalan la importancia y la necesidad del involucramiento masculino en el cuidado infantil, además del propio deseo de algunos varones de participar de las decisiones y de la división de las tareas domésticas, destacando que su participación en el cuidado es clave para alcanzar la equidad de género (Aguayo, F., Barker, G. y E. Kimelman, 2016).

Podríamos definir al cuidado como el conjunto de "aquellas actividades y relaciones orientadas a alcanzar los requerimientos físicos y emocionales de niños y adultos dependientes, así como los marcos normativos, económicos y sociales dentro de los cuales éstas son asignadas y llevadas a cabo” (Daly y Lewis, 2000). Asimismo, hablar de cuidado implica tener en cuenta múltiples dimensiones asociadas. Siguiendo a Batthyany (2004). en tanto producción de bienes y actividades que permiten a las personas alimentarse, educarse, estar sanas y vivir en un espacio propicio, abarca tanto el cuidado material que implica un trabajo, el cuidado económico que implica un costo y el cuidado psicológico que implica un vínculo afectivo. Por otra parte, la especificidad del trabajo de cuidado es la de estar basado en lo 
relacional, ya sea en el contexto familiar o por fuera de él. En el marco de la familia, su carácter a la vez obligatorio y percibido frecuentemente como desinteresado, le otorga una dimensión moral y emocional (Batthyany, 2013).

En consonancia, la crianza es entendida como un proceso (Aguirre, 2000) que implica tres dimensiones: las pautas de crianza, las prácticas de crianza y las creencias acerca de la crianza. Por un lado, las pautas se relacionan con la normatividad que siguen los padres frente al comportamiento de los hijos siendo portadoras de significaciones sociales. Por otro lado, las prácticas de crianza se ubican en el contexto de las relaciones entre los miembros de la familia donde los padres juegan un papel importante en la educación de sus hijos. Las prácticas son acciones, comportamientos aprendidos de los padres ya sea a raíz de su propia educación como por imitación y se exponen para guiar las conductas de los niños. Finalmente, las creencias hacen referencia al conocimiento acerca de cómo se debe criar un niño. Si bien el cuidado y la crianza son conceptos diferentes ${ }^{3}$, su consideración conjunta potencia el desarrollo de nuestra investigación porque nos permite introducirnos y conocer las prácticas cotidianas domésticas desarrolladas por los jóvenes.

En los últimos años, la agenda feminista ha incorporado con fuerza la noción de Economía del Cuidado. El concepto da cuenta de la modalidad que una sociedad adopta para organizar los temas relativos al cuidado, es decir, mediante qué forma se define la provisión y se garantiza el acceso a estos servicios. Las decisiones y políticas que se adoptan en este campo son de suma importancia ya que pueden habilitar o restringir la disponibilidad de tiempo de la población, y por ende, sus capacidades y opciones.

Indudablemente, la forma en que se organiza la provisión del cuidado en una sociedad, tiene importantes repercusiones en términos de la igualdad de género: la misma puede continuar confinando a las mujeres a su rol de cuidadoras asociado a ideas tradicionales relacionadas con la feminidad y la maternidad, o bien, mediante la provisión de servicios de cuidado, “socializar" estas tareas y abrir opciones para la participación femenina en la economía (Razavi, 2007).

En la misma dirección, la organización social del cuidado refiere a la manera en que las familias, el Estado, el mercado y las organizaciones comunitarias de manera conjunta, producen y distribuyen cuidado (Pautassi y Rodríguez Enríquez, 2014). En las sociedades modernas capitalistas, la familia ocupa un lugar central en esta organización, lo cual permeó el modo cómo se estructuraron los sistemas de protección social en América Latina, que asumieron que el "cuidado” se trataba de una cuestión privada, de la cual tiene que encargarse la familia. Actualmente, los cuidados no constituyen un componente de los sistemas de protección social en la región. Esta cuestión, por ende, no ha ingresado como una esfera que haya que regular o proteger (Provoste Fernández, 2012). Si bien hay avances en algunos instrumentos de política, las acciones presentan debilidades para proveer una respuesta integral y esos vacíos agudizan los problemas vinculados 
con cambios en la estructura demográfica, complejización de las familias, modificación en los patrones de empleo y participación económica de las mujeres y los/as jóvenes.

La situación de la población joven con responsabilidades de cuidado adquiere un lugar destacado para pensar trayectorias de inclusión social, teniendo en cuenta especialmente la debilidad de las políticas públicas para proveer respuestas integrales. La escasa infraestructura pública de cuidados destinada a la primera infancia, refuerza el rol de las familias y las mujeres e impacta en las trayectorias educativas y laborales de los jóvenes (De León, 2016). Así, las familias de estratos socioeconómicos más altos terciarizan parte o toda la responsabilidad del cuidado a través de la contratación de ayuda doméstica o de servicios privados, mientras que las de menores ingresos recurren a "mecanismos adaptativos" (comparten intergeneracionalmente las tareas de cuidado o retiran la participación de las mujeres en el mercado de trabajo) que incrementan su vulnerabilidad (Filgueira, 2007; CEPAL, 2009).

La Encuesta Nacional de Juventud (ENJ, 2014) indica que el 29 \% de los/as jóvenes entre 15 y 29 años en Argentina tiene hijos a cargo.De este modo, casi 4 de cada 10 tiene responsabilidades de cuidado, especialmente de niños/as(el 34\% de los jóvenes cuida niños habitualmente, dentro o fuera de su propio hogar y un 3\% a ancianos). Sin embargo, este diagnóstico destaca una diferencia de género importante: mientras el 24\% de los varones jóvenes realiza actividades de cuidado, este porcentaje aumenta a 48\% en el caso de las mujeres (ENJ, 2014).

Dicha encuesta también destaca que las actividades de cuidado tienen una incidencia mayor entre los jóvenes provenientes de hogares de bajos ingresos.Así,el 44\% que vive en hogares de bajos ingresos realizan actividades de cuidado, mientrasque en hogares de sectores medios asciende a $26 \%$. Sin embargo, la mayor diferencia se produce en el grupo de jóvenes que no estudia, no trabaja, ni busca trabajo y se encuentra en el estrato de ingresos del hogar más bajo: lejos de estar ocioso, este grupo se dedica a cuidar a otras personas (De León, 2016).

De esta forma, el impacto de las obligaciones de cuidado sobre la situación laboral de los/asjóvenes es contundente: 1 de cada 4 jóvenes no trabajaban (al momento de realización de la encuesta) por sus obligaciones familiares (23,8\%); aunque este motivo es manifestado mayormente por las mujeres, donde el 36,2\% declararon no hacerlo por esta causa. Asimismo, el 10,6\% de las mujeres no trabajaron por embarazo o maternidad (ENJ, 2014).

Lo más destacable, sin dudas, es el obstáculo que representan las responsabilidades de cuidado para sostener la presencia en el mercado de trabajo o el estudio. Poco más de 3 de cada 10 jóvenes que cuidan niños dejó de trabajar, de estudiar o tuvo que trabajar menos horas para realizar esta tarea. Mientras entre las mujeres se traduce en 42,1\%, la proporción de varones asciendea $12,9 \%$. 
Ahora bien, ¿qué es lo que sucede con los varones y el cuidado? ¿Qué prácticas de cuidado realizan los jóvenes? ¿Qué arreglos de trabajo/ cuidado realizan las familias (y otras instituciones) para proveer estos cuidados? ¿Qué tipos de arreglos contribuyen a la equidad de género? ¿Cuáles, por el contrario, refuerzan estereotipos de género? ¿Cuánto del cuidado de niños/as se desplaza al espacio público, mediante el uso de servicios estatales, comunitarios o privados? Estas son algunas preguntas que guían este trabajo.

\section{Metodología}

Para poder indagar sobre las experiencias de paternidad y cuidado de jóvenes en contextos de vulnerabilidad social, la investigación adoptó un diseño flexible y un abordaje metodológico cualitativo. Utilizamos la entrevista semiestructurada para adentrarnos en los espacios en los que se desarrollan los jóvenes y explorar así el mundo de la vida cotidiana (Piovani, 2007).

Las entrevistas fueron realizadas a jóvenes varones padres de un barrio popular de la localidad de Los Hornos (La Plata). en base a una muestra intencional seleccionada por bola de nieve, a partir de los criterios de accesibilidad y heterogeneidad. Loscuarenta jóvenes entrevistados fueron informados de la naturaleza de la investigación, del objetivo, la pertinencia, el anonimato y la confidencialidad de la información, pidiéndose su consentimiento por escrito.En la muestra, además incluimos sieteentrevistas a actores significativos del barrio en cuestión, específicamente profesionales de salud y referentes barriales y sociales.

Para complementar y enriquecer a la entrevista, utilizamos la observación participante como una de las estrategias empleadas para construir datos referidos a los espacios barriales en los que participan y desarrollan los jóvenes indagando dimensiones no registrables en la entrevista. El acceso a los hogares estuvo garantizado por los contactos previos con la comunidad.

La mayoría de los entrevistados se emplean como albañiles o ayudantes de albañil, otros como electricistas, y en menor proporción, como cooperativistas de Argentina Trabaja o cooperativas municipales de barrido de calles y poda de árboles. Muy pocos se dedican a la chatarra (recolección, trozado y venta de chatarra) o al cirujeo.En 4 casos, detectamos que los jóvenes son beneficiarios del Programa PROG.R.ES.AR ${ }^{4}$, que además de ser un incentivo económico para la finalización de estudios, estipula la prestación de servicios de cuidado para los jóvenes que tienen responsabilidades familiares, aunque ninguno de los entrevistados estuviera al tanto de este dato. Previamente a ser beneficiarios del programa, éstos 4 jóvenes se empleaban como recuperadores de residuos en la planta recicladora perteneciente a una cooperativa municipal, aledaña al asentamiento. 
De los cuarenta entrevistados sólo dos poseen un "trabajo en blanco" o registrado a partir de su sindicato (UOCRA, sindicato de la rama de la construcción).

\section{Resultados}

En sintonía con los datos anteriormente presentados, en nuestra investigación encontramos que los sujetos entrevistados adoptan, en general, una postura "colaboradora” en relación al cuidado. Esto implica queayudan a sus parejas en los hogares, pero la responsabilidad principal es casi exclusiva de las mujeres. No obstante, en un número significativo de casos hallamos que las tareas en el hogar son asumidas de manera más equitativa, aunque cercanas a lo que podríamos denominar "cuidados periféricos”, entre los que se destacan loslúdicos(deportes o juegos)y también los administrativos (llevar a los hijos/as al centro de salud, retirarlos de los jardines de infantes, hacer un trámite o certificados como la $\mathrm{AUH}^{5}$ ). En este sentido, es llamativa la rigurosidad que algunos jóvenes manifiestan respecto a la atención médica de sus hijos/as, teniendo en cuenta que casi la totalidad de los entrevistados no recuerda haber asistido a un establecimiento médico por controles o aplicación de vacunas. Incluso uno de los casos -como el de Fernando- expresa no tener libreta sanitaria. La mayoría de los jóvenes asistieron solo en situaciones concretas de urgencia (sutura de brazos, cabeza, quebraduras o esguinces, fiebre muy elevada).

Es preciso introducir, sin embargo, una diferencia temporal y de género en el cuidado (al menos en nuestro universo de estudio): si se tratade hijos recién nacidos, bebés (menores al año) ó de niños; como también en hijos varones o mujeres.

En el primer caso, y especialmente los meses iniciales de vida, hallamos que los jóvenes entrevistados no encuentran un lugar en el cuidado. Más allá de las razones biológicas que caracterizan ese momento vital, que centra la atención en la relación madre-bebé, estos expresaron sentirse "raros”, "perdidos”, “que no sabían bien qué hacer”. En ese sentido, no colaboraban y quedaban "autoexcluidos" de ese proceso, aunque muchos se encontraran familiarizados con estas tareas, por el cuidado de hermanos menores o sobrinos previo a su paternidad:

"Los primeros días, mi mujer se encargaba de las cosas del bebé y yo la ayudaba con lo que podía. Cambio pañales porque me crié con mis sobrinos, o sea, ayudé a mi hermana a criar a mis sobrinos, entiendo de esas cosas. Pero en ese entonces no me salía el papel de padre. Era como que ella le cambiaba los pañales y yo me quedaba como... raro, y te digo más, no lo quería alzar hasta que cumpliera dos meses por miedo a que lo lastimara, como era tan chiquito y yo era muy bruto. Por ejemplo, ahora tiene cuatro meses y ya se acostumbró a la brutalidad, cómo juego a lo bruto. Cuando el bebé tenía dos meses 
sin quererlo mordí. No me di cuenta de la fuerza y lo dejé llorando. Era como algo delicado que no lo podía tratar bruscamente.Pero cuando [mi pareja] me dice "amor hace esto", lo hago. Para llevarlo a la salita,vamos los dos pero si es por ejemplo darle la vacuna, de las tres que tiene que tener, habré faltado una”(Francisco, 19 años, 1 hijo)

Un dato interesante es que los jóvenes entrevistados construyen una relación de cuidado diferente entre sus hijos varones o mujeres. Respecto a los primeros, los jóvenes se mostraban más entusiasmados e involucrados en su crianza, incluso algunos manifestaron llevarlos consigo a sus trabajos, en el caso que lo tuvieran, para mostrarles "lo que hacían". Además, expresaron pasar más tiempo con ellos, jugar a la pelota y otros

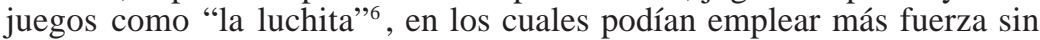
preocuparse por lastimarlos. En contrapartida, el cuidado de las hijas mujeres quedaba preferentemente en manos de sus parejas, dado que debían ser tratadas con mayor delicadeza, entre las mismas mujeres, y que no podían apelar ni compartir los mismos juegos. El baño, el cambio de pañales o vestimenta tampoco es compartido con sus hijas, expresando que al realizar alguna maniobra pudieran lastimarlas, o generar algún conflicto al entrar en contacto con ellas por ser varones, más allá de que sean sus padres.

En losrelatos de los jóvenes, también observamos que para ellos tener un hijo varón posee un valor superiora que sea mujer, como continuadores de un legado familiar, responsables de la descendencia y el reconocimiento ante los demás.

"Cuando nacieron los nenes, yo cambiaba los pañales, todo, los bañaba. A Bruno, a la nena no. Las nenas con las nenas y los nenes con los nenes. Yo bañaba a Bruno. "A vos que te bañe tu mamá”, le decía a mi hija. Vos sos nena, con la mamá.Estaba mi sobrina acá [en casa] también, "vamos a bañarla”, “¡no!, bañala vos”. Es que las nenas se tienen que bañar con las nenas, ¿cómo vas a estar bañando vos a las nenas?

E:-¿¿Y sentiste lo mismo cuando nació Bruno que María?

R:-¡No! Bruno es otra cosa. El varón, ¡era varón! El varón es todo.

E:-Ah, entonces ahora que viene [está por nacer] otro varón, ¿estás más contento?

R:-¡Sí! ¡Los dos varones! Que sea como yo, así le puedo enseñar todo lo que sé de mecánica, de autos.

E:-Pero María también puede aprender algunas cosas, ¿̇o no?

R:- No, no necesariamente. Te rompe todo, te tira todo, no quiere armar nada. No le gustan esas cosas a ella. (José, 20 años, 3 hijos)

“Queríamos tener un varón. Y para un hombre tener su primer hijo varón, no sé tal vez queda como machista pero para mí es, qué sé yo, es tu generación (sic). Vos decís, el día de mañana o tus nietitos van a ser tal, van a llevar tu apellido. En cambio la nena, vos le ponés tu apellido y después cuando ella tiene tus nietos, no van a ser tu 
descendencia. Se corta ahí. En cambio, yo veía que si tenía un varoncito, ya iba a tener descendencia. Si me decía mi señora, “vamos a ponerle mi apellido”, yo le digo que no. Yo la quiero reconocer como el papá. Es mi apellido”. (Alejo, 19 años, 2 hijos)

En relación a la experiencia con sus propios padres, los jóvenes afirmaron que "cuidan más” y de otro modo a sus hijos. Al menos la mitad de los entrevistados no conoció a su padre biológico y adoptó un padre de crianza,definido por ellos mismos, al que consideran como el padre en sentido estricto. La presencia o ausencia/abandono es lo que determina ese rótulo. Aquellos que tuvieron a su padre presente en sus hogares, expresaron que el ejercicio de la violencia (especialmente los castigos físicos) era parte cotidiana de su crianza, aunque no pueden explicar el por qué. Esto resulta llamativo, ya que la violencia no es naturalizada; es denunciada, aunque sí es legitimada. En este aspecto en particular, se reconocían muy diferentes con sus hijos: la violencia física no es aceptada en su estilo de crianza y tampoco tolerada en otros amigos o vecinos jóvenes que tengan hijos.

"Yo no entendía por qué mi viejo me trataba tan mal. Me agarraba con una manguera y me dejaba todo marcado. Por ahí me iba a cazar a pajaritos con los pibes del barrio. ¡Todas esas cosas que hace uno de chico! Y mi viejo me llamaba ¡Alan! Cuando llegaba [a casa], ya me mataba a palos. Me agarraba con la manguera, tenía un cable de esos de antena y me arruinaba. Mi vieja siempre se peleaba porque mi viejo era muy bruto para educarnos. No se medía una vez que se encarnecía [sic]. Con mis hermanas tan así no era. Pero cuando se enloquecía, no le importaba nada. Si mi vieja no nos sacaba, hoy en día capaz... Yo lo amo a mi viejo, no tengo rencor, fue su forma de educarme y ya está yo lo tomo así y a veces le agradezco "gracias viejo por los valores que me diste, por la educación que me diste, te agradezco".Tal vez no fue la manera, yo no lo hago con mis hijos, pero te lo agradezco. Y para mí es eso, que yo nunca lo vi a mi viejo borracho, nunca me enteré. He conocido gente en la calle que lo conocía a mi viejo de pibe, nunca me enteré que se drogó, me dijeron “Tu viejo, un tipazo”, “tu viejo, mirá que nosotros le ofrecíamos [droga], tu viejo nunca agarró nada, un tipazo, un laburador, laburador de la casa, nunca le pegó a tu mamá, nunca” y así”.(Alan, 23 años)

\section{E: ¿Y vos sentís que sos diferente con Juana?}

e: Sí, olvidate. [Una vez mi papá] me fue a llevar al jardín y se fue y no me fue a buscar más. Se olvidó. Pero bueno, nunca más... Casi lo mato a mi viejo yo, le di un tiro una vez. Le pegaba mucho a mi vieja, yo ya era grande, tenía 14 años, entonces le di [un tiro]. Yo ya andaba en la joda, la delincuencia, de vago

$\mathrm{E}$ : ¿Y qué pasó después?

e: No, ahora no me dedico a eso, me dedico a laburar y hacer las cosas bien, para estar bien, porque si yo estoy encerrado [preso], 
¿quién la va a proteger a mi hija? Nadie

E: ¿Pero tenés contacto con él ahora?

e: No, no lo veo, si lo veo ni lo saludo, nada. No tengo nada que ver con ese chabón, con esa persona, no tengo nada que ver. Se portó muy mal cuando nosotros éramos chicos. Yo pienso a veces en mi papá, las cosas que hizo el chabón, no me quería tener ni nada. Me pegaba...Cuando me veía en la esquina así, me pegaba para llevarme a mi casa. Hasta que me enojé y bueno, pasó lo que tenía que pasar. (Federico, 21 años)

De este modo, se pueden establecer algunos puntos de continuidad y ruptura en las prácticas de cuidado que respondena un modelo tradicional o hegemónico de paternidad (la idea del legado o la trascendencia a través de los hijos, proveer, proteger) con otros emergentes ${ }^{7}$ (Bonino, 2003) que critican, se distancian o reconfiguran algunas de sus dimensiones anteriormente aceptadas (la crítica a una crianza violenta, el acompañamiento a sus hijos/as)

\section{"Nadie cuida como la familia"}

Otra dimensión vinculada a los cuidados explorada en nuestra investigación es su externalización o tercerización, es decir, laposibilidad de trasladar las tareas de cuidado por fuera de los hogares. Como mencionamos en la primera sección, las familias de estratos socioeconómicos más altos terciarizan parte o toda la responsabilidad del cuidado a través de la contratación de ayuda doméstica o de servicios privados, mientras que las de menores ingresos recurren a "mecanismos adaptativos" (comparten intergeneracionalmente las tareas de cuidado o retiran la participación de las mujeres en el mercado de trabajo) que incrementan su vulnerabilidad (Filgueira, 2007; CEPAL, 2009). especialmente en las trayectorias laborales y educativas de los y las jóvenes.

Al respecto, De León (2016) señala que no es posible conocer la proporción de niños y niñas que concurren a un establecimiento de cuidados cuyos padres sean jóvenes. Dada la baja cobertura de este instrumento de política en nuestro país, sería lógico pensar que existe un porcentaje importante de población joven con hijos que no tiene asegurado un espacio público de cuidado.

En el caso de la localidad del barrio analizado, observamos que las únicas instituciones establecidas para niños de hasta 5 años son algunos jardines de infantes de gestión pública que, en modalidad de jornada simple, los reciben a partir de los 3 años. No visualizamos jardines maternales ni comunitarios, centros de desarrollo infantil (CeDI) o guarderías públicas

Recién a partir del Durante el mes de abril de 2017, se logró la aperturade un jardín maternal provincial a raíz de la presión ejercida por un movimiento de vecinosauto convocados ${ }^{8}$. Al margen de este espacio, en la 
localidad de Los Hornos no existen lugares alternativos al hogar para el cuidado de niños menores de 3 años que no sean jardines de infantes. Marisa Fournier (2017) señala que la falta de jardines estatales es un rasgo común a los barrios más empobrecidos de la periferia del conurbano bonaerense, donde la crisis de los cuidados se presenta de modo más dramático o contundente. Como contrapartida, la emergencia de jardines comunitarios, apuntalados por diversas organizaciones sociales con fuerte protagonismo femenino, absorben la demanda y cubren la vacancia estatal, "subsidiando una parte de la reproducción social e intergeneracional en territorios vulnerados" (ibíd., 2017, p. 100).

No obstante a esta demanda colectiva, no visualizamos en los testimonios de los varonesentrevistados la articulación de una petición concreta de un jardín maternal. Rara vez señalaron la necesidad o deseo de contar con instituciones públicas alternativas al cuidado doméstico y familiar. El cuidado como tal continúa siendo percibido como una responsabilidad de la esfera privada, doméstica, familiar; mientras que los ámbitos públicos, en especial los jardines de infantes, son vistos como espacios exclusivamente educativos.

En los relatos apreciamos que la decisión de la externalización del cuidado entre las parejas pocas veces es negociada o acordada. Una y otra vez se aluden a las imágenes de género tradicionales que establecen que las mujeres son quienes deben cuidar a sus hijos, especialmente si estos son aún bebés. Como indica Faur (2014). existe una "ideología maternalista", heredera del modelo de provisión masculina/cuidado femenino que define a la madre como mejor cuidadora posible de la familia o como "cuidadora ideal”, que se encuentra presente en los relatos de los jóvenes, como también en las diversas instituciones de salud o públicas en general que transitan.

“A ninguno de los dos nos gustan las guarderías. Los dos tenemos el mismo pensamiento: nadie la va a cuidar [a nuestra hija] como la cuidamos nosotros. O como la cuida la familia. Entonces tenemos ese pensamiento y a veces si salimos la dejamos con mi mamá o con la mamá de ella” (Guillermo, 18 años)

"No, no, por ahora mientras yo lo pueda mantener [al hogar] prefiero que se quede [mi pareja] tranquila en mi casa y no que salga a la mañana a cagarse de frío, no se tenga que mojar, prefiero hacerlo yo y que mis hijos estén con la madre. Sé lo que es no tener la mamá. Que se críen con la madre y estén con la madre” (Fernando, 20 años, 2 hijos)

Sin embargo, son destacables los testimonios de Alan y Eugenio. Si bien coinciden parcialmente con la postura de madre como cuidadora ideal, ambos consideran al cuidado de los hijos/as como un trabajo. Eugenio, incluso, manifiesta que este debiera ser remunerado económicamente, es decir, contemplarse como cualquier empleo extra doméstico. 
“Tuvimos un acuerdo con mi señora. Le dije: "Yo no te voy a pedir que vos trabajes ni nada, te vas a quedar en la casa”. Lo único que quiero es que, porque las hermanas de ella, sí trabajan. Por ahí es mejor para la economía de la casa pero tenés descuidado a tu hijo, por ahí no sabes con quién lo dejás y todas esas cosas. Por ahí a tu hijo no le podés dar la educación más o menos entre los dos, viste. Y yo le dije "vos quedate en casa, cuidá los nenes y hacé los labores de la casa, ese es tu trabajo"

$\mathrm{E}:$ ¿Vos consideras eso como un trabajo?

e: Yo considero eso como un trabajo. Yo le decía, vos querés trabajar, trabajá en la casa. Tu trabajo es cuidar bien a los nenes. (Alan, 23 años 3 hijos)

"El padre puede pensar que tiene que trabajar, tiene que romperse el lomo, ¿¿no? pero la madre estando en la casa también tiene que romperse el lomo, pero de otra manera: estando con el bebé, haciendo las cosas de la casa. Es todo un trabajo eso, no sé por qué no les pagan [a las mujeres] por ser amas de casa, porque es un re bondi”(Eugenio, 19 años, 1 hijo)

El temor a dejar a los hijos al cuidado de otras personas que no sean sus madres o algún familiar cercano o de confianza, también es un motivo que refuerza el maternalismo, impidiendo que el mismo se socialice. Las noticias en los diarios o en la televisión, como también experiencias negativas de personas conocidas o cercanas sobre guarderías en donde los/as niños son maltratados o ignorados, alimentan esta ideología que ubica a las mujeres como cuidadoras innatas.

Otra razón que opera en las decisiones de cuidado es la económica. Es decir, la idea de sopesar el costo que implica el cuidado extra doméstico, lo que se traduce en un repliegue de las mujeres, principalmente, en los hogares ante la salida "inconducente" al mercado de trabajo. En este sentido, se organiza una estrategia familiar que pueda articular el ingreso (secundario) de dinero con la atención de los hijos.

"Mi señora no trabaja. Quiere laburar, le había puesto un kiosco en mi casa. Después el kiosco no caminaba, no funcionaba, así que lo cerramos. Vendía productos de belleza, siempre tratando de ayudarme. Pero más allá de que me decía "yo quiero salir a trabajar”, está todo bien, vos salís a trabajar, ponele que ganás 4 lucas, tenés que pagar la niñera, una persona que lo venga a cuidar, vas a tener que trabajar para pagarle a otra persona. Entonces es mejor que se quede en casa” (Fernando, 20 años).

De este modo, podemos visualizar que la responsabilidad principal del cuidado de los hijos, recae en la mayoría de los casos que analizamos, en las mujeres o en familiares muy cercanos (madre, suegra, cuñada, vecina). preferentemente mujeres. Sin embargo, lejos de pensar que este cuidado se basa únicamente en un acto de solidaridad, este es remunerado entre fami- 
liares. Se produce lo que Faur (2014) denomina una"microeconomía del cuidado": la persona que queda a cargo de familiares (por ejemplo, sobrinos) participa en una estrategia tendiente a aliviar su propia situación de pobreza, en un contexto difícil para emplearse. Así, obtiene una retribución por una "contraprestación” al realizar el trabajo.

"Mi mujer tenía que cuidar a la nena [sobrina] para que la hermana empiece a laburar, de ahí le iba a dar plata también. Entonces la hermana de ella se va a laburar y mi señora se queda con la nena [propia] y las otras nenas, las sobrinas vendría a ser, y las cuida a las sobrinas y a la hija también” (Federico, 21 años)

Cabe destacar esto último, ya que nos lleva a reflexionar que la actividad de cuidado, como sosteníamos anteriormente a partir de los relatos de los jóvenes, posee un valor y que se retribuye económicamente como tal. La antropóloga catalana Dolors Comas d'Argemir (2016) plantea que la valorización del trabajo de cuidado consiste en un primer paso para la construcción de relaciones más equitativas al interior de los hogares, pero también, como un trabajo que puede ser comparado y equiparado al trabajo extra-doméstico. Asimismo, lo visualiza como una estrategia para incorporar a los varones al cuidado.

Vinculado a la esfera laboral, no registramos “tensiones” en los testimonios. Nos referimos a que los jóvenes no manifiestan mayores alteraciones o cambios con sus trabajos a partir del nacimiento y crianza de sus hijos, principalmente. No observamos "tironeos" ni preguntas acerca de cómo se reorganizará su trabajo en función del hijo/a, o planteos como regresar antes de sus trabajos para estar más tiempo con los hijos/as en el hogar.

Ante la posibilidad que sus parejas busquen y consigan un empleo, y que los entrevistados sean los encargados principales del cuidado de sus hijos, encontramos cierto consenso que denota incomodidad con lasituación hipotética planteada. Además de la fuerte concepción que las mujeres deben criar a sus propios hijos, especialmente en los primeros meses de vida, términos como "mantenido", "vago”, "mujer/mamá”, "estar encerrado”, son puestas al mismo nivel para definir sus sensaciones al quedar como responsables centrales del cuidado. La realización de la situación hipotética aparece con mayores posibilidades cuanto más grandes son los niños y por tanto, no se identifica un cuidado de carácter intensivo u omnipresente. A pesar de esta aceptación, el trabajo (extra-doméstico). en la mayor parte de los casos, parece definir a los varones y no podrían renunciar a él.

Si tu mujer empezara a trabajar y vos te tuvieras que quedar con Ana en tu casa, ¿qué pensarías? Me sentiría incómodo, pero estaría bueno. No sé, [yo] sería como la mamá y el papá a la vez(Ramón, 22 años, 1 hija)

Como pudimos observar, la "ideología maternalista” se encuentra no solo en los relatos de los jóvenes que entrevistamos, sino que es apuntala- 
da por imágenes y discursos que operan desde las propias políticas sociales y las instituciones públicas de cuidado (que se destacan por su ausencia). retroalimentándose mutuamente. A su vez, la baja institucionalidad del jardín maternal legitima la escasez de provisión pública y gratuita, mientras que el relativo vacío de la oferta estatal no estimula la mercantilización del servicio y, en última instancia, impacta sobre la desigualdad social, en la medida en que los niños/as más pobres son los/as que menos oportunidades tienen de asistir a jardines maternales, recargando la responsabilidad exclusiva del cuidado en los hogares.

\section{Discusión}

En este artículo presentamos algunos hallazgos preliminares y reflexiones sobre las prácticas de cuidado que desarrollan los jóvenes varones en sus hogares, en el marco de la tesis doctoral sobre paternidades juveniles en sectores populares que se encuentra en curso. Consideramos que estas prácticas se encuentran íntimamente ligadas al ejercicio de la paternidad y recuperarlas permite profundizar nuestra comprensión sobre las posibles formas que asumen las paternidades juveniles en contextos vulnerados, dando cuenta de su heterogeneidad.

A lo largo de este trabajo, encontramos que los sujetos entrevistados cuidan, en su mayoría, de manera colaborativa con sus parejas, aunque podemos observar casos en los cuales las tareas se organizan de un modo más equitativo. Comparativamente, los jóvenes entrevistados que conocieron a sus padres admiten que "cuidan más” y de otra forma a sus hijos/as (comparten más tiempo con sus propios hijos/as a través del juego, el deporte, colaboran en la realización de las tareas escolares).condenando el uso de la violencia en general y el empleo de castigos físicos, en particular.El entusiasmo y la preferencia del cuidado de los hijos varones sobre las hijas mujeres, es un dato llamativo que podría indicar la inauguración de un proceso de desigualdades dentro del hogar.

Sostenemos que estos jóvenes realizan prácticas de cuidado, pero dentro de las dimensiones que definimos como lúdica (jugar con los/as hijos/as; practicar un deporte o actividad con ellos/as) y también administrativa(llevar a los hijos/as al centro de salud, retirarlos de los jardines de infantes, hacer un trámite o certificados). Si bien éste último podría ser relacionadoen principio con prácticas más allegadas a la lógica maternalista, la dimensión lúdica o recreativa la excede y sugiere pensar en una mayor cercanía o involucramiento de los jóvenes entrevistados con el cuidado de sus hijos, comparativamente.

Podríamos entonces asociarla a una presencia pautada o puntual (es decir, episódica) en tanto que la responsabilidad principal del cuidado, en última instancia, continúa centrada en las mujeres(madres, suegras, hermanas, vecinas) de manera transversal u omnipresente, en tanto son consideradas cuidadoras innatas. No obstante, es considerable la referencia de los 
entrevistados al trabajo reproductivo (cocinar, limpiar) realizado por las mujeres en los hogares como un trabajo, en tanto es equiparado al empleo extra-doméstico.

De este modo, observamos la convivencia de algunos elementos o prácticas vinculadas al modelo tradicional o breadwinner(como el rol secundario o colaborador con los cuidados, la idea del legado o la trascendencia a través de los hijos, proveer, proteger) y elementos críticos o emergentes que tensionan este modelo y lo rechazan(la crítica a una crianza violenta, el acompañamiento a los hijos/as más allá del sostén económico, mayor presencia en los hogares, la consideración y equiparación del trabajo reproductivo que realizan las mujeres como un trabajoextra doméstico). Es en esta tensión donde ubicamos los relatos de las experiencias de paternidad de nuestros entrevistados.

Por último, un actor importante ineludible en este análisis son las políticas de cuidado. La falta de servicios de cuidado de primera infancia, especialmente de oferta pública y en contextos vulnerados refuerza y reafirma la ideología maternalista presente en gran parte de las instituciones, discursos y políticas sociales.Creemos que la ausencia de demanda de parte de los entrevistados varones de estos espacios de cuidado, se vinculan con la reproducción de estas imágenes y discursos en torno a la ideología maternalista. Lejos de volverse un instrumento de distribución de cuidado y equidad de género en los hogares,la vacancia estatal de jardines traslada su costo a los jardines comunitarios, que son sostenidos por organizaciones sociales encabezados principalmente por mujeres, nuevamente.La sinergia de todas estas situaciones va prefigurando escasos lugares para el cuidado masculino, desalentando su involucramiento y confinando su tipo de participación.

Consideramos que el cuidado constituye uno de los nudosdonde mejor se observanlas inequidades de género, como también de desigualdad social. Las políticas de Estado orientadas a la des-familiarización o socialización del cuidado, son fundamentales para comenzar a revertir esta tendencia y convocar a la corresponsabilidad. 


\section{Notas}

${ }^{1}$ Los nombres de los entrevistados han sido cambiados para preservar su identidad, así como la de sus hijos/as

${ }^{2}$ Este trabajo retoma los desarrollos teóricos de Fuller (2000), De Keijzer (2001, 2003) y Bonino (2003) que sugieren hablar de "paternidades” o "paternidades múltiples”, alejándose de las conceptualizaciones que la configuran como un tipo de relación, universal y predeterminada de los varones con sus hijos/as. La "paternidad" es entendida como una construcción social que cambia históricamente y tiene variaciones notables de una cultura a otra, así como entre las distintas clases sociales y etnias de un mismo país. Coincidimos con Fuller (2000, 2001) cuando plantea que la paternidad integra el conjunto de relaciones posibles que pueden establecerse entre un padre y sus hijos/as, sin reducirlo a la dimensión biológica, como "un campo de prácticas y significaciones culturales y sociales en torno a la reproducción, el vínculo que se establece o no con los/las hijos/as y su cuidado. Este campo de prácticas y significaciones emergen del entrecruzamiento de los discursos sociales que prescriben valores acerca de lo que es ser padre y producen guiones de los comportamientos reproductivos y parentales. Estos últimos varían según el momento del ciclo vital de las personas Asimismo, estas relaciones están marcadas por las jerarquías de edad, género, clase, raza y etnia” (Fuller, 2000, p. 37). Así como los autores/as mencionados (Fuller, 2000, Bonino, 2003) refieren a la existencia de paternidades o de paternidades múltiples, en nuestra investigación es posible pensar "paternidades juveniles" en plural, aludiendo a las diversas formas que asumen estas experiencias en jóvenes de barrios populares.

${ }^{3}$ En los trabajos consultados, los cuidados están asociados a la realización de actividades cotidianas con los hijos como bañarlos, vestirlos, alimentarlos, llevarlos a la escuela, al médico. La crianza implica formar y educar a los hijos (Carrasquer, Torns, Tejero y Romero,1998; Torres, 2006, Aguirre, 2007)

${ }^{4}$ El PROG.R.ES.AR brinda una ayuda económica destinada a los estudiantes entre 18 y 24 años que no tienen empleo, trabajan informalmente o formalmente, con un ingreso tope del titular y su familia de tres salarios mínimos, vitales y móviles. Se reconoce como grupo familiar autónomo a los jóvenes con hijos. En contrapartida a la asignación económica que reciben, los jóvenes que participan en el programa deben retomar, iniciar o continuar sus estudios, sean secundarios, universitarios, terciarios o cursos de formación profesional.

${ }^{5}$ El programa Asignación Universal por Hijo (AUH), se encuentra destinado a aquellos niños, niñas y adolescentes en condiciones de vulnerabilidad social que no cuentan con otra asignación familiar prevista por el régimen existente. Los titulares del beneficio son las madres y padres de los niños/as y adolescentes que sean monotributistas sociales, se encuentren desocupados o se desempeñen en la economía informal y perciban una remuneración inferior al salario mínimo, vital y móvil. También abarca a los padres trabajadores incorporados al Régimen Especial de Seguridad Social para Empleados del Servicio Doméstico que perciban un ingreso menor al salario mínimo, vital y móvil. Adicionalmente, por el Decreto N 446/11, en mayo de 2011 se creó la Asignación por Embarazo para Protección Social (AUE) que se abona a las mujeres embarazadas a partir de las doce semanas de gestación hasta el nacimiento o interrupción del embarazo 
${ }^{6}$ Es un juego de manos entre uno o más participantes en el cual se simula "pegar" trompadas y patadas a un oponente. Hace alusión a un ring de boxeo, de ahí deviene el nombre.

${ }^{7}$ Para R. Williams (1997:145) lo ‘emergente’ abarca los nuevos significados y valores, nuevas éticas, nuevas relaciones y tipos de relaciones que se crean continuamente como aquellos elementos que son alternativos o de oposición. Reconoce que es extremadamente difícil en muchos casos distinguir en el análisis los elementos nuevos, porque pueden constituir una nueva fase de la cultura dominante, de aquellos que son específica y claramente alternativos, es decir, de oposición a un sistema dominante.

${ }^{8}$ El grupo de vecinos autoconvocados“Ensanche Av.66 Los Hornos”, reclamó la construcción de un jardín maternal en la zona durante aproximadamente 12 años. Es el primer jardín maternal creado por fuera de la capital provincial (en La Plata existen actualmente 3 establecimientos públicos) y el primero en ser construido para tales fines. 


\section{Bibliografía}

Aguayo, F., Barker, G. y E. Kimelman, E. (2016). Paternidad y Cuidado en América Latina: Ausencias, Presencias y Transformaciones, Masculinities and Social Change, 5(2).98-106. doi:10.17583/ MCS.2016.2140

Aguirre, R. (2005). Os cuidados familiares como problema público y objeto de política Trabajo presentado en la Reunión de Expertos Políticas hacia las familias, protección e inclusión sociales. Santiago, Chile: Cepal.

Batthyány, K. (2004).Género, cuidados familiares y usos del tiempo

Batthyány, K. (2013). Perspectivas actuales y desafíos del Sistema de Cuidados en Uruguay. En L. Pautassi y C.Zibecchi (coords.) Las fronteras del Cuidado, agenda, derechos e infraestructura. Buenos Aires, Argentina: Ed. Biblos

Bonino, L. (2003).Las nuevas paternidades.EnCuadernos de Trabajo Social, (16) 171-182. Madrid, España: CTS-UAM.

Carrasquer, P., Torns, T., Romero, A. (1998). El trabajo reproductivo. Papers, Revista de Sociología, (55) 95-115.

CEPAL (2009).Panorama social de América Latina. Santiago, Chile: CEPAL

Daly, M. y Lewis, J (2000). The concept of social care and the analysis of contemporary welfare states,Medline Plus.Recuperado de: https:// www.ncbi.nlm.nih.gov/pubmed/10905001

D’Argemir, D. (2016).Hombres cuidadores: Barreras de género y modelos emergentes. Psicoperspectivas, 15(3).10-22. https://dx.doi.org/ 10.5027/psicoperspectivas-Vol15-Issue3-fulltext-750

DeKeijzer, B. (2000). Paternidades y transición de género. Fuller. Paternidades en América Latina. Lima, Perú: Fondo Editorial de la PontificiaUniversidad Católica del Perú.

De León, G. (2017). Jóvenes que cuidan: impactos en su inclusión social, Documento de trabajo $N^{\circ}$ 158, CIPPEC. Recuperado de: https:// www.cippec.org/wp-content/uploads/2017/04/158-DT-PS-Jovenesque-cuidan-Gimena-de-Leon-2017.pdf

Esquivel V. (2011).Atando Cabos, Deshaciendo Nudos. La economía del cuidado en América Latina. Poniendo a los cuidados en el centro de la agenda. Santiago, Chile: PNUD 
Faur, E. (2014).El cuidado infantil en el siglo XXI: mujeres malabaristas en una sociedad desigual.Buenos Aires, Argentina: Siglo Veintiuno Editores.

Filgueira, F. (2007). Cohesión, riesgo y arquitectura de protección social en América Latina, Serie Políticas Sociales 135, Santiago, Chile: CEPAL.

Fournier, M. (2017).La labor de las trabajadoras comunitarias de cuidado infantil en el conurbano bonaerense ¿Una forma de subsidio de "abajo hacia arriba”?.Trabajo y sociedad, (28), 83-108. Recuperado de http:/ /www.scielo.org.ar/scielo.php?script=sci_arttext\&pid= S151468712017000100005\&lng=es\&tlng=es.

Fuller, N.(2000). Significados y prácticas de la paternidad entre varones urbanos del Perú. Paternidades en América Latina. Lima, Perú: FondoEditorial de la Pontificia Universidad Católica del Perú.

Levtov, R., Van der Gaag, N., Greene, M., Kaufman, M., \& Barker, G. (2015). State of the World's Fathers: A MenCare Advocacy Publication. Washington, DC: Promundo, Rutgers, Save the Children, Sonke Gender Justice, and the MenEngage Alliance

Lupica, C. (2010).Trabajo decente y corresponsabilidad de los cuidados en Argentina Buenos Aires, Argentina: OIT

Piovani, J.I; Marradi, A., y Archenti, N. (2007). Metodología de las Ciencias Sociales.Buenos Aires; Argentina:Emecé.

Provoste Fernández, P. (2012).Protección social y redistribución del cuidado en América Latina y el Caribe: el ancho de las políticas. Santiago, Chile: CEPAL. Recuperado de https://repositorio.cepal.org/bitstream/ handle/11362/5850/1/LCl3560_es.pdf

Razavi, S. (2007). The political and social economy of care in a Development context. Conceptual issues, research questions and policy options.Gender and Development Paper (3). Recuperado de: http:// www.unrisd.org/80256B3C005BCCF9/(httpAuxPages)/ 2DBE6A93350A7783C12573240036D5A0/\$file/Razavi-paper.pdf

Rodríguez, C. y Pautassi, L. (2014). La Organización Social del Cuidado de Niños y Niñas. Elementos para la construcción de una agenda de cuidados en Argentina. Buenos Aires, Argentina: Equipo Latinoamericano de Justicia y Género- ELA

Sarkadi, A., Kristiansson, R., Oberklaid, F. \&Bremberg, S. (2008). Fathers’ involvement and children's developmental outcomes: a systematic review of longitudinal studies. ActaPcediatrica(97), 153-158. Retrieved from http://www.ncbi.nlm.nih.gov/pubmed/18052995 
Williams, R. (1997).Marxismo y literatura. Barcelona, España: Península

Recibido: 01.05.18

Aceptado: 31.07.18 